\title{
Modulación de la apoptosis por citomegalovirus en la perspectiva del sistema nervioso central
}

\author{
Hilda M. González-Sánchez, Ana S. Silva-Ramírez y Claudia Castillo Martín del Campo
}

\footnotetext{
Facultad de Medicina, Universidad Autónoma de San Luis Potosí. San Luis Potosí, S.L.P., México.

Laboratorio de Células Troncales Humanas, CIACYT (HMGS, CCMdC)

Laboratorio de Fisiología Celular (ASSR)

Los autores declaran no tener conflictos de interés sobre la publicación de este artículo.

Recibido: 14 de abril de 2015 Aceptado: 19 de noviembre de

Correspondencia a: Claudia Castillo Martín del Campo claudiacastillo@gmail.com
}

\section{Modulation of apoptosis by cytomegalovirus, from the perspective of the central nervous system}

Apoptosis is one of the most effective mechanisms against the spread of pathogens such as viruses. However, viruses have developed measures to counter the protective role of apoptosis in infected cells. Cytomegalovirus (CMV) represents the major cause of congenital infection worldwide triggering important damage in the developing central nervous system (CNS). Several mechanisms of apoptosis prevention during CMV infection have been described, among them, viral proteins and RNAs are capable of prevent apoptosis by the intrinsic and extrinsic pathways as well as the one mediated by stress in the endoplasmic reticulum. Nevertheless, the CMV pro-apoptotic effect remains enigmatic and it has been suggested as a bystander effect in non-infected cells. This review summarizes the mechanisms by which CMV modulates the signaling pathways involved in apoptosis. It also includes a brief description of the permissiveness of the CNS to CMV infection and the generated cell death after infection, which may relate to the observed damage during a congenital infection.

Key words: Apoptosis, cytomegalovirus, congenital infection, viral infection, programmed cell death.

Palabras clave: Apoptosis, citomegalovirus, infección congénita., infección viral, muerte celular programada.

\section{Introducción}<smiles>[CH3]</smiles>
itomegalovirus (CMV) es un virus de replicación lenta perteneciente a la familia Herpesviridae, cuyo genoma de ADN lineal bicatenario se expresa de forma temporal durante la infección ${ }^{1}$. La replicación de CMV está asociada a la expresión secuencial de tres clases de genes; los genes inmediatos tempranos (IE del inglés immediate early), los genes tempranos (E, early) y los genes tardíos (L, late). Inicialmente los genes IE son transcritos para tomar control de la síntesis celular de macromoléculas y facilitar la expresión de los genes E, los cuales a su vez controlan la producción de viriones y estimulan la transcripción de los componentes estructurales del virión, es decir de los genes L. De esta manera, el genoma es expresado en forma de cascada dando lugar a la formación de partículas virales completas ${ }^{1}$.

Estudios epidemiológicos han registrado un alto índice de seropositividad en población abierta adulta, de $60-100 \%$ en países desarrollados y cercano al $100 \%$ en países en desarrollo ${ }^{1-3}$. Las poblaciones especialmente susceptibles son: receptores de trasplantes, infectados con el virus de la inmunodeficiencia humana y, de forma importante, fetos y recién nacidos ${ }^{4}$. En este contexto, la infección intrauterina por CMV es la causa más frecuente de defectos al nacimiento, especialmente en el sistema nervioso central (SNC). La incidencia de la infección congénita por CMV se encuentra entre 0,8 y $2,6 \%$ del total de recién nacidos a nivel global, porcentaje del cual entre 5 y $10 \%$ presenta una enfermedad de inclusión citomegálica al nacimiento con síntomas que incluyen microcefalia, hidrocefalia y calcificaciones cerebrales. De la misma manera, el grupo de infantes asintomáticos puede desarrollar trastornos cerebrales como pérdida de la audición y retraso mental ${ }^{5}$.

El CMV humano tiene la capacidad para infectar y replicarse en una amplia variedad de células, incluyendo: células epiteliales, células de músculo liso, fibroblastos, macrófagos y hepatocitos, entre otras ${ }^{2,6}$. El vasto tropismo celular de CMV podría ser la causa de la dispersión sistémica del virus dentro del cuerpo humano y de su diseminación entre hospederos ${ }^{6}$. Tras una infección primaria, CMV puede permanecer en el organismo de forma latente para ser reactivado en períodos de inmunosupresión ${ }^{4}$. Dicha cronicidad puede ser atribuida a diversos mecanismos virales de evasión tales como la interferencia con la presentación de antígenos por el complejo mayor de histocompatibilidad clase I y clase II; la disminución de la expresión de receptores del ácido N-metil-d-aspártico (NMDA) para evitar la muerte excitotóxica mediada por glutamato en hipocampo o por los efectos en la muerte celular programada tipo I conocida como apoptosis ${ }^{7,8}$.

\section{Objetivo}

El objetivo del presente trabajo fue examinar los mecanismos de modulación de CMV con el proceso normal de 
apoptosis descritos previamente en la literatura científica, destacando el daño generado en SNC.

\section{Desarrollo}

\section{Comprendiendo el proceso de apoptosis}

- El término apoptosis y su importancia biológica.

El término "apoptosis" fue acuñado por primera vez en 1972 por Kerr, Wyllie y Currie, para describir un proceso de muerte celular programada, al hacer una analogía de este término griego que describe la caída de las hojas en el otoño con un proceso de muerte natural y necesario; tanto es así que es de suma importancia durante el desarrollo, la morfogénesis y el mantenimiento de la homeostasis ${ }^{9}$. La apoptosis juega un papel central durante el desarrollo neural, proceso en el cual entre el $30 \mathrm{y}$ el $80 \%$ de las células neuronales que se generan mueren por apoptosis en la etapa embrionaria y la vida postnatal temprana incluyendo células madre en proliferación y neuronas postmitóticas ${ }^{10}$. Estudios en modelos animales han permitido determinar que el bloqueo de la apoptosis durante el desarrollo da lugar a la formación de estructuras cerebrales desorganizadas y sobredesarrolladas como crecimientos ectópicos e hiperplasias ${ }^{10}$.

Además de su papel en el desarrollo, la apoptosis también desempeña una tarea importante en la respuesta inmune durante la selección negativa de células $\mathrm{T}$ autoreactivas en el bazo, la eliminación de células activadas innecesarias y en la supresión de células infectadas con patógenos. Por lo anterior, es de esperarse que cualquier tipo de falla en el proceso apoptótico culmine en trastornos como cáncer, enfermedades autoinmunes y diseminación de infecciones virales. De la misma manera, la falta de control en este proceso ha sido relacionado a la incidencia de desórdenes neurodegenerativos, SIDA y enfermedades isquémicas ${ }^{11}$. Enfermedades como Alzheimer, Parkinson y esclerosis amiotrófica lateral así como la pérdida neuronal posterior a un infarto o trauma también pueden involucrar un trastorno apoptótico ${ }^{12}$.

\section{- Descripción molecular}

Los procesos de apoptosis suelen ser mediados por serin-proteasas denominadas caspasas, las cuales son sintetizadas como zimógenos (procaspasas) y posteriormente activadas mediante la remoción del prodominio y la subsecuente formación de un tetrámero de dos subunidades pequeñas y dos grandes ${ }^{13}$. Dependiendo del sitio de acción las caspasas apoptóticas pueden dividirse en iniciadoras y efectoras. Las caspasas iniciadoras están encargadas de empezar la cascada proteolítica que termina en la activación de las caspasas efectoras, pueden contener un prodominio del tipo CARD (dominio de reclutamiento y activación de caspasas) o del tipo DED (dominio efector de muerte) que determinan la conexión entre el estímulo de muerte y las cascadas proteolíticas (Figura 1A). Los blancos de las caspasas efectoras incluyen enzimas reparadoras de $\mathrm{ADN}$, proteínas del ciclo celular, reguladores de apoptosis y proteínas estructurales del citoesqueleto, con lo cual el daño es irreparable y culminará en la muerte celular $^{11,13}$. Son reconocidas tres vías de señalización clásicas que desembocan en la muerte celular por apoptosis: la llamada vía de los receptores o vía extrínseca, la vía mitocondrial o intrínseca y la mediada por estrés en el retículo endoplásmico $(\mathrm{RE})$.

\section{Inhibición de la apoptosis por CMV.}

- El papel de UL37 y el ARN B2.7 en la vía intrínseca de la apoptosis

La vía intrínseca o mitocondrial es iniciada por eventos en el interior celular que provocan en la mitocondria la liberación del citocromo c y de otras moléculas proapoptóticas del espacio intermembranal. A la fecha, se cree que la liberación del citocromo c se produce por la formación del conocido "poro de transición de permeabilidad mitocondrial" (MPTP) formado por la interacción entre un transportador de nucleótidos de adenina (ANT) en la membrana mitocondrial interna y un canal aniónico dependiente de voltaje (VDAC) en la membrana mitocondrial externa (MME), posiblemente con la participación de las moléculas denominadas Bax y Bak. Sin embargo, también se ha especulado que Bax y Bak podrían ser las formadoras del MPTP ${ }^{10,14}$. El citocromo c en el citoplasma se une a una molécula denominada Apaf-1 (factor activador de proteasas apoptóticas 1) con la subsecuente formación de heptámeros llamados apoptosoma. Apaf-1 contiene un dominio CARD que le permite interaccionar con la procaspasa- 9 activándola y permitiendo la activación de las caspasas efectoras ${ }^{11,13}$. El papel más importante en la regulación de la apoptosis lo desempeñan las proteínas de la familia Bcl-2, la cual contiene tanto miembros pro-apoptóticos como anti-apoptóticos con regiones conservadas denominadas dominios de homología Bcl-2 (Figura 1B). Después de estímulos pro-apoptóticos, Bax (que es principalmente citosólico) trasloca a la mitocondria, oligomeriza y se inserta en la MME induciendo la formación del MPTP. Por otra parte, Bak inhibido basalmente por Bcl- $\mathrm{X}_{\mathrm{L}}$ o Mcl-1 en la MME puede ser activado mediante la degradación del factor anti-apoptótico por proteínas $\mathrm{BH} 3$ para que Bak, ahora libre, oligomerice de forma semejante que $\mathrm{Bax}^{14}$.

UL37 es uno de los genes de CMV humano cuyo producto ha sido señalado como anti-apoptótico y se le ha denominado inhibidor viral de apoptosis localizado en mitocondria (vMIA) debido a que previene la liberación del citocromo c y con ello la activación de caspasas con dominios del tipo CARD. A pesar de que vMIA no comparte homología con proteínas de la familia Bcl-2, 


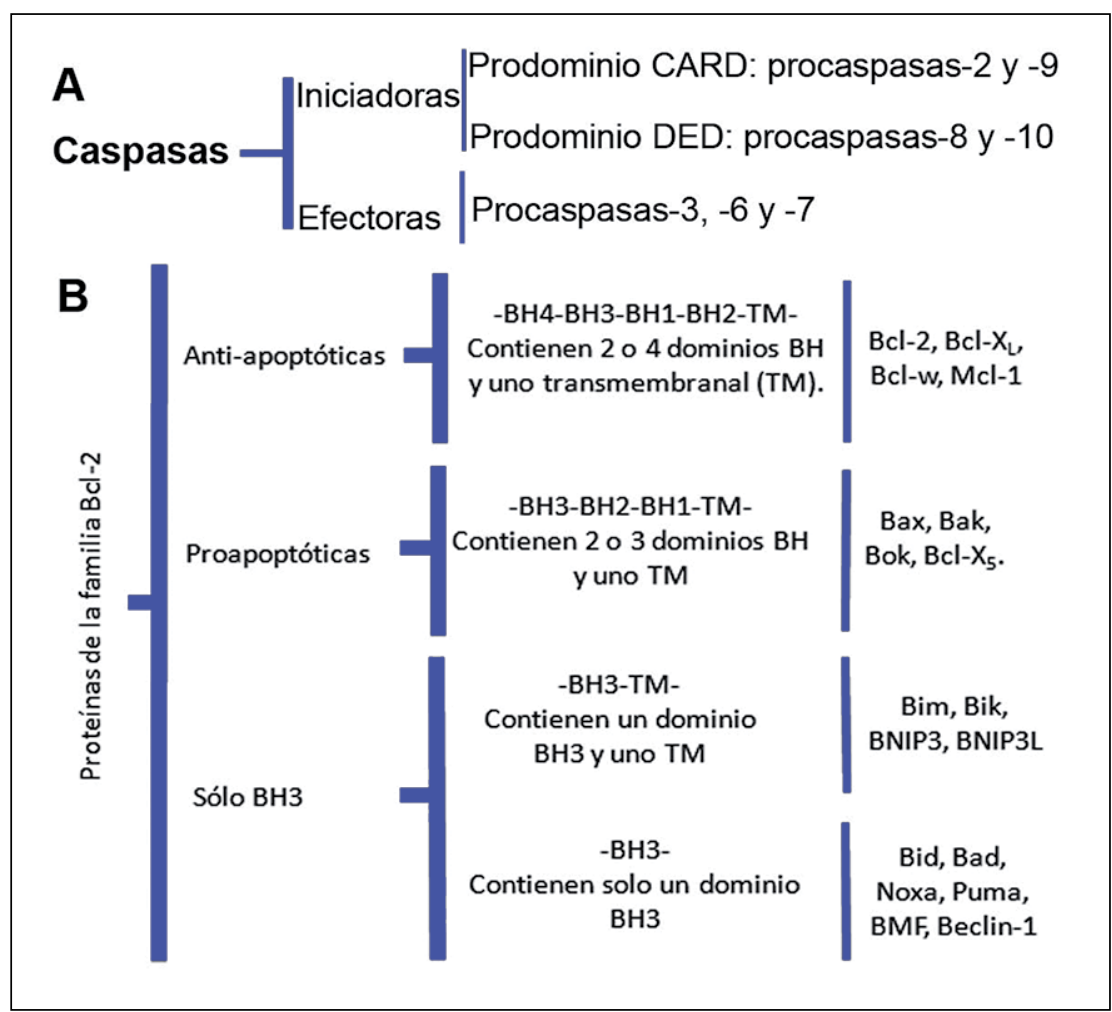

Figura 1. Caspasas y proteínas de la familia Bcl-2. (A) Las caspasas involucradas en la apoptosis se clasifican como iniciadoras y efectoras, dentro del grupo de las iniciadoras se encuentran dos tipos, aquellas que tienen un prodominio de tipo CARD y las del tipo DED, de lo cual depende su participación en las vías intrínseca o extrínseca, respectivamente. (B) Clasificación de las proteínas de la familia Bcl-268.

sus funciones son semejantes ya que evita la permeabilización de la mitocondria, posiblemente al secuestrar a los oligómeros de Bax, aunque se cree también tiene efecto en la función de $\mathrm{Bak}^{15,16}$. En el CMV murino han sido identificadas las proteínas $\mathrm{m} 41.1$ que actúa sobre Bak y m38.5 que actúa sobre Bax; sin embargo, en el caso de CMV humano, vMIA podría cumplir con ambas funciones ${ }^{16,17}$. Los mecanismos por los cuales vMIA ejerce sus efectos anti-apoptóticos no han sido completamente dilucidados; es posible que participe en la inhibición de la apoptosis a través de más de una vía. vMIA es sintetizado en la membrana del RE, donde permanece anclado a la membrana a través un extremo N-terminal hidrofóbico y transita hacia contactos del RE con la mitocondria denominados membranas asociadas a mitocondria (MAM) ${ }^{18}$. En las regiones MAM, vMIA regula la homeostasis del calcio y combate las respuestas de estrés celular que pueden desembocar en apoptosis ${ }^{19}$. Recientemente, se evidenció que vMIA puede reclutar a Bax hacia las MAM donde es marcada para su degradación proteosomal, ejerciendo de esta manera un mecanismo redundante para bloquear la actividad apoptótica de Bax en la célula infectada ${ }^{19}$.
Otra forma mediante la cual CMV combate el estrés celular y evita la apoptosis es mediante el ARN de $2.7 \mathrm{~kb}$ ( $\beta 2.7)$, el cual es transcrito pero no codifica para productos traducidos funcionales ${ }^{20}$. El efecto anti-apoptótico de ARN $\beta 2.7$ está dado por la interacción de éste con el complejo 1 mitocondrial (NAD oxido-reductasa), el que es capaz de inducir apoptosis bajo ciertas condiciones como enfermedades mitocondriales y factores ambientale ${ }^{21}$. El ARN $\beta 2.7$ interacciona específicamente con la subunidad GRIM-19 (genes asociados con la mortalidad inducida por retinoides/interferon) esencial para el ensamblaje y función del complejo 1. El complejo 1 activo soporta la formación del gradiente electroquímico necesario para la producción de ATP, por lo que su interacción con el ARN $\beta 2.7$ sugiere que el virus estabiliza el gradiente manteniendo la producción de energía ${ }^{22}$. Por otra parte, es bien sabido que vMIA igualmente promueve la estabilidad de la membrana mitocondrial, siendo activo predominantemente en etapas tardías de la infección ${ }^{23}$; sin embargo, el ARN $\beta 2.7$ es expresado de forma abundante en etapas mucho más tempranas de la infección $\left(12\right.$ a 24 h) ${ }^{22}$.

\section{- Inhibición de la vía extrínseca de la apoptosis.} participación de UL36

Como se mencionó anteriormente, la apoptosis puede ser también inducida por la unión de los receptores de la muerte con su ligando. Dichos receptores son proteínas transmembranales que pertenecen a la familia del receptor del factor de necrosis tumoral (TNFR). Se incluyen los receptores de Fas (CD95), TNFR y los receptores de TRAIL (ligando inductor de apoptosis relacionado a TNF), que contienen un dominio de muerte (DD) en la cola citoplásmica. La señalización de dichos receptores puede ser simplificada como la unión del receptor con su respectivo ligando que estimula el reclutamiento de una molécula adaptadora FADD (dominio de la muerte asociado a Fas) o TRADD (dominio de la muerte asociado a TNFR) $)^{11,24}$. Dichos adaptadores poseen un dominio DED y uno DD, lo cual le permite unirse al receptor de la muerte por un lado, y por otro a una caspasa iniciadora que contiene un homólogo DED. El complejo formado recibe el nombre de complejo de señalización inductor de la muerte (DISC) y permite la agregación y autoactivación de procaspasas-8, que a su vez activarán a una caspasa efectora como la caspasa- $3^{13}$. En este proceso pueden intervenir proteínas anti-apoptóticas que son denominadas FLIP (proteínas inhibidoras de FLICE:enzima convertidora de interleucina-1 $\beta$ tipo FADD), y cuya función es la inhibición de la activación de la procaspasa-8 al competir por FADD, ya que estas proteínas también contienen un dominio DED ${ }^{19}$.

La proteína codificada por el gen de CMV humano UL36 denominada inhibidor de la apoptosis inducida por caspasa- 8 (vICA) previene la muerte celular mediada 
por receptores a través de un mecanismo semejante a los reguladores FLIP, al unirse a la procaspasa- 8 evitando su interacción y activación con la proteína adaptadora FADD. Es de notar que vICA no posee homología en su secuencia aminoacídica con los FLIPs y de forma más relevante, que no contiene el dominio $\mathrm{DED}^{25}$. Todos los CMV de los cuales se cuenta con su secuencia contienen homólogos de vICA lo que hace suponer que este es un mecanismo anti-apoptótico importante en la patogénesis viral ${ }^{15}$. De manera interesante, en el modelo murino se ha encontrado que el homólogo de vICA de CMV murino codificado por el gen M36 es importante para la capacidad infectiva del virus. Empleando líneas celulares y cultivos primarios de macrófagos se demostró que el virus murino deficiente del gen M36 no puede replicarse de manera elevada en este tipo celular; sin embargo, el crecimiento en fibroblastos no se ve alterado ${ }^{26}$. Además, ha sido probado que la ausencia del gen M36 afecta severamente la replicación viral in vivo, y que el efecto puede ser revertido al reemplazar el gen M36 por un dominante negativo de FAAD $^{27}$. Los resultados indican que la apoptosis limita la replicación del virus en ciertos tipos celulares. Recientemente, se demostró que el bloqueo de la apoptosis mediado por M36 en macrófagos permite la replicación viral, como consecuencia de la protección proporcionada a las células infectadas frente al TNF $\alpha$ secretado por este tipo celular 27. Por su parte, la falta de bloqueo de la apoptosis por el virus carente de M36 en hospederos inmunosuprimidos (ratones deficientes de linfocitos) confirmó el papel que juega M36 en la replicación viral in vivo, debido a que la replicación del virus fue miles de veces menor que aquella mostrada en animales inmunosuprimidos infectados con el virus silvestre ${ }^{27}$. La deleción del gen M36 hace a las células infectadas con CMV murino susceptibles a la acción de los macrófagos, lo cual le confiere el potencial de ser un blanco terapéutico para pacientes inmunodeprimidos. Por otro lado, interfiriendo también con la apoptosis por la vía de los receptores, se ha observado que monocitos no infectados son capaces de incrementar la liberación de TNF al medio extracelular en presencia de células infectadas, aunque por su parte el virus disminuye la expresión de TNFR1 en la superficie de la célula infectada como otro mecanismo anti-apoptótico ${ }^{28,29}$.

\section{- Apoptosis inducida por estrés en el retículo endoplásmico y el papel de la proteína UL38}

Tras estímulos de estrés como acumulación de grandes cantidades de glicoproteínas, fallas en la homeostasis del calcio o acumulación de proteínas no plegadas, el RE activa tres vías denominadas UPRs (respuesta de las proteínas mal plegadas) que inicialmente pretenden restablecer la homeostasis atenuando la traducción y activando la maquinaria proteosomal para la eliminación de proteínas mal plegadas ${ }^{30,31}$. Sin embargo, después de estímulos de estrés prolongado se activan vías pro-apoptóticas que involucran a la enzima dependiente de inositol 1 (IRE1), enzima que a su vez activa a la quinasa N-terminal c-Jun (JNK) cuyos blancos serán la activación de las proteínas Puma y Noxa y la inhibición de Bcl-2, por mecanismos dependientes e independientes del gen supresor de tumores $p 53^{30,31}$.

pUL38, una proteína codificada por el gen UL38 de CMV humano, bloquea la activación de vías pro-apoptóticas inducidas por estrés en el RE. Hasta el momento se considera al gen $U L 38$ específico de los betaherpesvirus, sus homológos han sido identificados en los herpesvirus 6 y 7 ; no obstante, se ha encontrado conservado entre las diferentes especies de $\mathrm{CMV}^{31}$. El papel anti-apoptótico de pUL38 está dado al inhibir la fosforilación de JNK y al aumentar la expresión de ATF4 (factor de activación transcripcional 4) una proteína involucrada en la respuesta

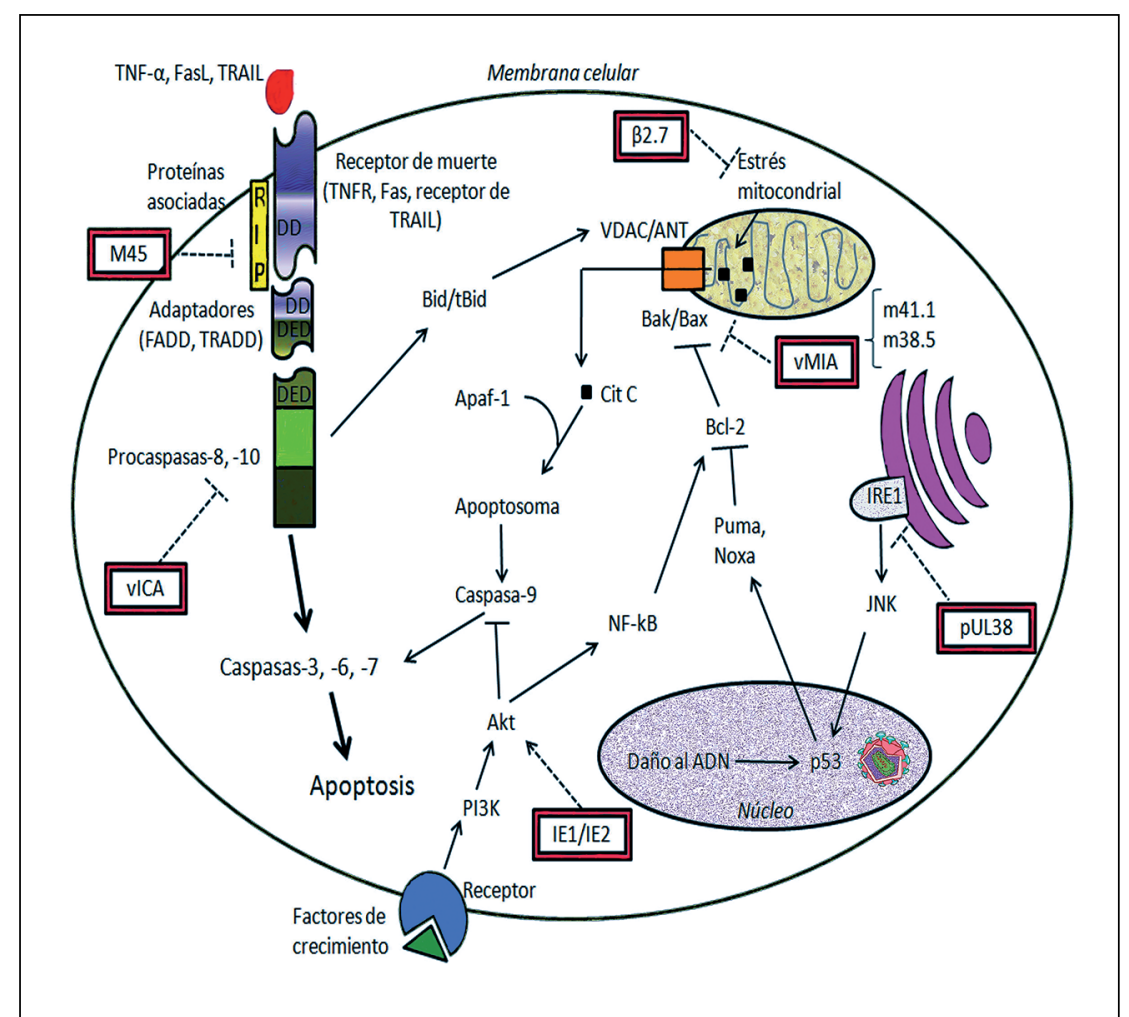

Figura 2. Vías de señalización implicadas en la apoptosis y su modulación por citomegalovirus. En los recuadros se muestran las proteínas y ARN no codificante del virus que presentan efectos inhibidor $(-)$ o estimulante $(\rightarrow)$ sobre las vías de la apoptosis. Las proteínas vICA y M45 bloquean la muerte celular mediada por receptores. M45 de CMV murino interacciona con la proteína RIP-1 evitando su señalización, mientras que vICA se une a la procaspasa-8 evitando su interacción y activación con la proteína adaptadora FADD. vMIA del CMV humano y sus homológos m41.1 y m38.5 de CMV murino previenen la liberación del citocromo c y con ello la activación de caspasas con dominios del tipo CARD, posiblemente secuestrando a la proteína Bax. El ARN $\beta 2.7$ interacciona con el complejo 1 mitocondrial reduciendo el estrés en la mitocondria. La proteína pUL38 de CMV humano bloquea la activación de vías pro-apoptóticas inducidas por estrés en el RE al inhibir la fosforilación de JNK. IE1 e IE2 activan una vía de sobrevivencia mediada por Akt. 
anti-oxidante con lo que controla la expresión génica para adaptar las células al estrés y así evitar la activación de eventos que lleven a la muerte celular, como $\mathrm{JNK}^{31}$.

\section{- La función de las proteínas IE1 e IE2 en la sobrevivencia de las células infectadas}

Alrededor de los procesos apoptóticos hay una gran regulación y convergencia con otras vías, como la de las quinasas JNK estimulando la vía pro-apoptótica y a través del factor nuclear kappa $\mathrm{B}(\mathrm{NF}-\mathrm{kB})$ la vía anti-apoptótica ${ }^{11}$. Se ha observado que NF-kB puede incrementar la expresión de Bcl-X ${ }_{L}$, Bcl-2 y de IAPs (proteínas inhibidoras de apoptosis). Otra forma de regulación es mediada por la quinasa Akt, la cual es activada por fosfatidilinositol-3'$\mathrm{OH}$ quinasa (PI3K) en respuesta a múltiples estímulos como insulina y el factor de crecimiento insulinoide (IGF) que, tras su activación, fosforila e inactiva a factores proapoptóticos como Bad, caspasa-9, y a la IkB quinasa para activar a NF-kB. La presencia de factores de crecimiento evidencia vías de salvamento como lo revelan estudios donde se ha encontrado disminuido el número de neuronas apoptóticas en el cerebelo y la corteza cerebral tras la adición de IGF, así como una fuerte dependencia del factor de crecimiento nervioso (NGF) para la sobrevivencia de neuronas simpáticas ${ }^{32,33}$.

Las primeras proteínas de CMV identificadas por sus propiedades anti-apoptóticas fueron los productos de los genes IE1 e IE2. El mecanismo mediante el cual IE1 e IE2 activan la vía de sobrevivencia corresponde a una vía mediada por Akt. A pesar de que aún se desconoce cómo es que esto ocurre dada la localización nuclear de estas proteínas y la ubicación asociada a la membrana plasmática de la PI3K, se cree que dicho proceso pudiera ocurrir por medio de un mecanismo transcripcional, aunque no se descarta que estos productos virales pudieran actuar directamente en el citoplasma ${ }^{34}$. En el caso de los Herpesvirus, se ha descrito que la activación de la vía de PI3K/Akt puede involucrarse en múltiples pasos durante el ciclo viral como la entrada del virus a la célula, la liberación de proteínas del tegumento, la replicación viral y la latencia y reactivación ${ }^{35}$. En el caso de CMV y de virus herpes simplex (VHS), la adhesión y la unión a receptores inducen la señalización por la vía de $\mathrm{PI} 3 \mathrm{~K} /$ $\mathrm{Akt}^{35}$. La síntesis de proteínas por parte de CMV es dispensable durante la primera fase da activación, pero necesaria para la segunda fase. La activación de Akt puede ser mediada primeramente por la unión de la glicoproteína $\mathrm{B}$ de CMV a las células, lo cual induce la fosforilación del receptor del factor de crecimiento derivado de plaquetas (PDGFR)- $\alpha$, el cual interacciona con la subunidad p85 de PI3K activando $\mathrm{Akt}^{36}$. Para la activación de la vía por un período de tiempo más prolongado, es necesaria la expresión de las proteínas virales IE1 e IE2 durante la fase de replicación viral, donde el incremento en la actividad de PI3K puede mediar el incremento en la expresión de factores anti-apoptóticos como c-FLIP ${ }^{35,37}$.

Por otra parte, si bien se desconoce la función que cumple p53 en la replicación de CMV, se ha observado que la inducción de p53 es necesaria para potenciar la replicación viral en células permisivas y ocurre varias horas después de la infección. La activación de p53 puede llevar al arresto del ciclo celular para permitir la reparación del ADN, o a la inducción de apoptosis posiblemente por la represión de proteínas anti-apoptóticas como Bcl-2. A este respecto, se ha sugerido que la proteína IE2 tiene la capacidad de unirse a p53 e inactivarla o bien, que está inactivación ocurra a través del incremento en la expresión de la isoforma dominante negativa de p73, con la capacidad de inactivar a p73 y a p53, dado que también se ve incrementada su expresión tras la infección con CMV humano ${ }^{38}$.

\section{- Incremento en la expresión de proteínas celulares anti-apoptóticas}

A pesar de la amplia gama de tipos celulares que son susceptibles a la infección con CMV y en los cuales puede ocurrir infección lítica, la infección latente se ha encontrado restringida a la subpoblación de células hematopoyéticas CD4+ del linaje mieloide ${ }^{39}$. El establecimiento de la infección latente en los monocitos tiene repercusiones importantes, ya que es responsable de la diseminación hematógena del virus. En este contexto, la inhibición de la apoptosis es un proceso crucial para el establecimiento de la latencia. Normalmente, el tiempo de vida de los monocitos en circulación es de 1 a 3 días; sin embargo, cuando éstos se encuentran infectados pueden permanecer viables por semanas ${ }^{40}$, lo cual evidencia la inducción de señales anti-apoptóticas. En 2010, Chan y cols. demostraron que la sobre-expresión de la vía de PI3K inducía el incremento en la expresión de Mcl-1, un miembro de la familia Bcl-2, en monocitos infectados ${ }^{40}$. Se demostró que la activación del receptor del factor de crecimiento epidermal, a través de la señalización por la vía de PI3K, conducía a la sobre-expresión de Mcl-1 y que este evento era esencial para evitar la apoptosis en los monocitos infectados y asegurar los primeros pasos en la estrategia de persistencia viral ${ }^{40}$. Por otra parte, además de la incrementada expresión de Mcl-1, se encontró correlación con un incremento en la activación de la vía de ERK, lo cual generaría un ambiente celular favorable para la sobrevivencia celular y el establecimiento de la latencia ${ }^{41}$. Se ha sugerido que tanto la activación de ERK como la subsecuente sobre-expresión de Mcl-1, jueguen un papel importante en la sobrevivencia de los progenitores mieloides hematopoyéticos y en el establecimiento de la latencia en las células mieloides ${ }^{41,42}$. Recientemente, la inducción de la señalización a través de la vía de ERK y la sobre-expresión de moléculas celulares anti-apoptóticas 
ha sido demostrada en fibroblastos humanos, mostrando que estos procesos influyen en la inhibición de la apoptosis en otros linajes celulares. Además del incremento en la expresión de la proteína Mcl-1, se encontró que la activación de la vía de ERK inducía la sobre-expresión de otra proteína anti-apoptótica denominada Bag- $1^{43}$. De forma interesante, se ha encontrado que la sobre-expresión de Bag-1 también es inducida como un mecanismo antiapoptótico en otros patógenos como el VHS tipo 2 y la bacteria Clamidia trachomatis ${ }^{44,45}$.

\section{- El papel de los microRNAs en la inducción de apoptosis}

Recientemente, fue reportado un estudio in silico que especula sobre la función de un par de microRNAs codificados por el genoma de CMV humano que pudiesen estar implicados en la inhibición de genes apoptóticos. El miR-UL70-3p, al unirse a la region 3'-UTR del gen MOAP-1 (modulador de apoptosis 1), evitaría la polimerización de Bax y la liberación del citocromo c, además, de inhibir la activación de la vía de los receptores ${ }^{21}$. Por otra parte, miR-UL148D puede inhibir las vías intrínsecas al interaccionar con los genes PHAP1 (proteínas asociadas a HLA-DR) y ERN1 (señalización RE a núcleo 1), los que promueven la activación de la caspasa-9 y la apoptosis inducida por estrés en el RE, respectivamente. Este estudio muestra que la maquinaria de miRNAs virales también pueden participar en la regulación negativa de los mecanismos antivirales humanos y actuar de forma sinérgica con las proteínas codificadas por su genoma ${ }^{21}$.

Finalmente, como reguladores de la actividad antiapoptótica, tenemos a la proteína M45 de CMV murino, la cual es capaz de interaccionar con la proteína de interacción con los receptores RIP-1 y RIP-3, a través de interacción homotípica con uno de sus dominios. RIP-1 juega un papel importante en la señalización mediada por receptores que llevan a la muerte celular por apoptosis, mientras que RIP-3 funciona como regulador de RIP-1 bajo ciertas circunstancias ${ }^{46}$. Además RIP-1 tiene la capacidad de actuar como quinasa involucrándose en procesos como autofagia y necrosis, por lo que la interferencia de CMV con sus funciones podría tener aún más relevancia, sin embargo, el homólogo UL45 de CMV humano parece no cumplir con el mismo cometido ${ }^{46,47}$.

\section{El efecto pro-apoptótico de CMV}

Contrarrestando la amplia diversidad de factores anti-apoptóticos generados por CMV, ha sido reportada la inducción de apoptosis en algunos tipos celulares. Inicialmente se identificó la capacidad del virus para inducir apoptosis en fibroblastos cuando estos fueron infectados con una mutante de CMV humano que carecía de los genes UL36 y UL37, y se encontró que este proceso podía ser revertido por la inserción de un gen anti-apoptótico ${ }^{48,49}$.
A pesar de esto, ningún gen pro-apoptótico de CMV que apoyara estas observaciones había sido descrito hasta el momento. Posteriormente, se logró la identificación de una proteína pro-apoptótica que es codificada por el gen US28 de CMV humano y que corresponde a una proteína IE que es un receptor de quimiocinas. Esta proteína es capaz de inducir apoptosis en varios tipos celulares, a través de la activación de las caspasas 8 y 10 . Se encontró además que la inducción de la muerte celular por parte de US28 puede ser prevenida por la expresión de c-FLIP y de la proteína anti-apoptótica $\mathrm{IE} 1^{50}$, sugiriendo que la inducción o bloqueo de la apoptosis son procesos altamente regulados que dependen tanto de factores virales como celulares. Se cree que la proteína US28 podría actuar como receptor de quimiocinas, activador de fosfolipasa $\mathrm{C}$ o factor pro-apoptótico, dependiendo de los niveles de expresión de las proteínas anti-apoptóticas celulares o virales ${ }^{50}$. Es decir, por estas funciones podría estar involucrada tanto en la diseminación viral como en la evasión de la respuesta inmune.

Apoyando la noción de que CMV es capaz de inducir apoptosis, se encontró que en etapas tempranas de la infección, la proteína IE2 conduce a la sobre-expresión del ligando de Fas (FasL) en células epiteliales de retina infectadas con CMV humano ${ }^{51}$. Tras la infección, se incrementó la secreción de FasL en el medio de cultivo, siendo comprobado este hallazgo al cultivar células Jurkat en presencia de medio proveniente de las células de retina infectadas y evidenciándose una alta tasa de apoptosis ${ }^{51}$. Además, las concentraciones de FasL en el humor vítreo de las pacientes con SIDA infectados con CMV era mayor que en aquellos no infectados con $\mathrm{CMV}^{51}$. Es bien sabido que la infección por $\mathrm{CMV}$ en los ojos humanos causa muerte celular y profundas disfunciones visuales. Este incremento en la secreción de FasL podría ser la causa de la pérdida de visión en las personas afectadas con retinitis por $\mathrm{CMV}^{51}$. Como consecuencia de este hallazgo, se piensa que CMV puede ser capaz de eliminar células vecinas con potencial letal para su célula hospedera, causando un efecto espectador, ya que CMV cuenta con una amplia gama de mediadores anti-apoptóticos que pueden evitar la muerte en las células infectadas.

Al parecer durante las primeras etapas de la infección se generan las primeras señales pro-apoptóticas que pueden ser sobrellevadas por CMV al incrementar la expresión de una amplia variedad de mediadores antiapoptóticos virales. Los procesos involucrados con la entrada viral proveen una protección transitoria contra la muerte celular, posteriormente, ciertos genes son expresados para asegurar la latencia de los genomas virales en el interior celular ${ }^{41}$. Ciertamente, si el virus es incapaz de inhibir estos eventos iniciales de inducción de la muerte celular, el establecimiento de la latencia se verá severamente afectado ${ }^{41}$. 


\section{Apoptosis inducida por CMV en el sistema nervioso central}

En el SNC, empleando el modelo murino se ha comprobado la permisibilidad a la infección por CMV en neuronas y células gliales, así como en células endoteliales, ependimales, microglia, entre otras. En estos estudios se ha visto que tanto neuronas como glia soportan la replicación viral, pero en ambos tipos celulares la infección culminó en muerte celular ${ }^{52}$. El CMV murino no presentó preferencias hacia algún tipo celular en particular, y se observó que el virus tiene la capacidad de infectar prácticamente cualquier tipo de células dentro del SNC. Sin embargo, se encontró una relativa preferencia hacia la glía radial que desempeña un importante papel durante la migración neuronal y por ello puede ser la causa de problemas corticales, como la microgiria encontrada en algunos pacientes con infección congénita ${ }^{52}$. Por otra parte, a diferencia de otros virus neurotrópicos como el VHS tipo 1 que tiene selectividad hacia ciertos tipos de neuronas ${ }^{53}$, en el caso de CMV la infección se encontró distribuida en varios tipos neuronales de diversas regiones cerebrales, incluyendo la corteza, el hipocampo, el estriado y el hipotálamo ${ }^{52}$. Además, cuando se infectaron cultivos de neuronas y astrocitos, se evidenció que en estos últimos se favorecía mayormente la replicación viral, obteniendo títulos virales más altos en menor tiempo, comprobando de esta manera que existen preferencias relativas del virus para infectar ciertos tipos celulares ${ }^{52}$.

Representando una infección congénita por CMV en un modelo murino in vivo se observó marcada pérdida neuronal. En este modelo se realizó la administración de CMV murino en los ventrículos cerebrales de embriones a los 15,5 días de gestación. Empleando marcajes inmunohistoquímicos y la técnica de TUNEL, se encontró cierto porcentaje de células en apoptosis que correspondían a neuronas; sin embargo, muy pocas de ellas resultaron positivas para la expresión de antígenos virales ${ }^{54}$. Además, la ubicación de las células en apoptosis no correspondía con la de las células infectadas detectadas por hibridación in situ. Estos hallazgos sugieren que la infección por CMV induce apoptosis, predominantemente en células que no se encuentran infectadas ${ }^{54}$. Esta posibilidad fue sustentada mediante un estudio in vitro empleando cultivos primarios de neuronas, en el cual se encontró que tras la infección con CMV murino las neuronas eran más resistentes a la ausencia de nutrientes o el tratamiento con glutamato que normalmente induciría apoptosis, además de que no se encontraron células infectadas TUNEL-positivas ${ }^{54}$. Por lo anterior, la inhibición de apoptosis en neuronas propone que es en estas células donde CMV humano establece latencia dentro del $\mathrm{SNC}^{5}$. Estos resultados sugieren que la apoptosis es inducida en las células que no se encuentran infectadas, a través de mecanismos indirectos como la liberación de un factor soluble como ocurre en las células de retina. Este efecto espectador, también ha sido reportado en otros estudios. En 2007, Ho y van den Pol, utilizando un co-cultivo de neuronas y astrocitos murinos, reportaron que los astrocitos se infectan inicialmente y posteriormente modifican la respuesta a estímulos de las neuronas no infectadas, afectando su señalización ${ }^{55}$. Por otro lado, pese a que el número de neuronas que se encontraron en apoptosis fue bajo, la inducción de la muerte neuronal puede ocasionar importantes alteraciones morfológicas y funcionales en el cerebro en desarrollo. Inesperadamente, en estos experimentos se encontró un alto porcentaje de microglia/macrófagos TUNEL-positivos, los cuales parecían haber fagocitado y no encontrarse apoptóticos siendo indicativo de que otras células apoptóticas hubieran sido removidas por microglia/macrófagos ${ }^{54}$. Además se ha reportado que la microglia activada produce proteinasas, quimiocinas y otras sustancias que pueden tener efectos citotóxicos sobre las neuronas, por ello la activación de la microglia como consecuencia de la infección viral puede causar indirectamente muerte neuronal ${ }^{54}$.

Con la finalidad de evaluar la capacidad de los diferentes tipos de células humanas del SNC para soportar la replicación de CMV, se realizó un abordaje infectando cultivos de microglia, astrocitos, neuronas y un cocultivo de astrocitos con neuronas con CMV humano. Los resultados indicaron que los astrocitos humanos fueron completamente permisivos para la infección con CMV, desarrollándose un extenso efecto citopático que culminó con la muerte celular ${ }^{56}$. Por su parte, cuando el co-cultivo con neuronas fue realizado, únicamente los astrocitos mostraron cambios relativos a la infección. Primeramente fueron evidentes cambios en la membrana plasmática sugiriendo que los astrocitos se encontraban en apoptosis; sin embargo, la fragmentación nuclear se observó hasta etapas tardías de la infección. En las células de la microglia y en los cultivos neuronales no se encontró evidencia de replicación viral ni expresión de genes virales, lo cual muestra que CMV humano presenta un mayor tropismo hacia el linaje astrocitario ${ }^{56}$. De manera interesante, la muerte celular de los astrocitos infectados parece ser postergada hasta que el pico de la replicación viral se presenta, similar a lo observado con el virus de la inmunodeficiencia humana tipo $1^{56,57}$.

Ha sido demostrado un incremento en la muerte celular en cultivos primarios y líneas celulares de células precursoras neurales (CPN) humanas identificando a este tipo celular como el blanco principal de CMV dentro del $\mathrm{SNC}^{58-60}$. Las CPN exhiben neurogénesis y tienen la capacidad de diferenciarse a cada uno de los linajes celulares del SNC, además dada la elevada proporción de este tipo celular en el cerebro en desarrollo, es un 
indicio de los daños que el virus cause durante una infección congénita. En estudios postmortem, analizando el cerebro de infantes con infección congénita, se encontró muerte celular por apoptosis principalmente en la zona periventricular la cual coincide con la localización de estas células ${ }^{61}$. Además, se determinó que las neuronas infectadas acumulan grandes cantidades de virus previo a su destrucción, tras la observación de células gigantes multinucleadas, lo cual puede causar el inicio del programa apoptótico ${ }^{61}$.

Empleando CPN humanas de origen fetal, se encontró que estas células son permisivas para la infección por CMV humano y que tras su infección pierden la capacidad para diferenciarse hacia neuronas y astrocitos cuando las CPN son infectadas al inicio de la diferenciación ${ }^{58,59}$. Estos eventos son dependientes de la replicación viral y de la expresión de proteínas tardías. Además de encontrarse disminuida la proliferación, las CPN infectadas entraron en apoptosis a los siete días de la inducción de la diferenciación $^{58}$. No obstante, no se determinó si eran las células infectadas o las no infectadas las que sufrían apoptosis. Recientemente, se ha estudiado el efecto del virus sobre CPN humanas derivadas de células pluripotenciales inducidas (iPSC). A través de la técnica de TUNEL y de la detección de las caspasas 3 y 9, logró evidenciarse que las células que sufrían apoptosis eran mayoritariamente las que se encontraban infectadas ${ }^{62}$. Además, se evidenció que la apoptosis fue causada por disfunción mitocondrial y por estrés en el RE, dado que se detectó la liberación del citocromo c en citoplasma y encontraron fosforiladas proteínas involucradas en la vía de las UPRs, incluyendo PERK, JNK, IRE1 $\alpha$ e IF $2 \alpha^{62}$.

Por otro parte, ha sido reportado que la susceptibilidad de las CPN al CMV depende de su grado de diferenciación. Empleado dos líneas celulares de CPN, una línea celular de neuroblastoma y una línea de células madre neurales humanas (hNS-1) se analizó la susceptibilidad a CMV humano. Se encontró que las células mayormente diferenciadas mostraban efectos más severos de la infección, mientras que las células hNS-1 presentaron efectos mínimos ${ }^{63}$. Posteriormente, al diferenciar a las células hNS-1 infectadas se evidenció un efecto citopático más notorio, un mayor número de células infectadas e incremento en la muerte celular, evidenciando el papel que juega el grado de diferenciación con la adquisición de la susceptibilidad al CMV y, consecuentemente, en la inducción de la muerte celular ${ }^{63}$. El incremento en la susceptibilidad tras la diferenciación puede ser consecuencia de modificaciones celulares que afecten uno o más pasos en el proceso infeccioso, como pueden ser la adherencia, entrada, tráfico intracelular, penetración al núcleo y actividad de los promotores ${ }^{64}$.

Dada su importancia en la infección congénita por $\mathrm{CMV}$, son necesarios más estudios que logren esclarecer qué ocurre con las CPN y con otras células del SNC en las que ocurre apoptosis, ¿son las células infectadas las que sufren apoptosis o son las inductoras? Ambas alternativas plantean un panorama poco favorable para el cerebro en desarrollo, y su resolución puede ayudarnos a diseñar mejores estrategias para el control de los daños ocasionados por este patógeno.

\section{Conclusiones}

La apoptosis es un mecanismo de defensa antiviral importante el cual se ha encontrado ser manipulable por diversos virus incluyendo CMV. Es de notar que la mayoría de los genes supresores de muerte en el genoma de CMV se encuentran agrupados, pareciendo tener una región específicamente destinada para ello. Por otra parte, su origen evolutivo es un enigma, ya que muchas de sus proteínas no presentan homología con algún producto celular, lo que denota la necesidad de continuar con el estudio de este campo ante la alternativa de la existencia de supresores de muerte celulares que aún no han sido descritos ${ }^{25}$.

El efecto de CMV predominantemente es considerado anti-apoptótico, pero parece ser dependiente de múltiples factores como la cepa viral empleada, el tiempo postinfección, la dosis viral y de forma importante del tipo celular infectado. El efecto de algunos inhibidores virales es diferente al tratarse de células que expresan solamente algún tipo de receptor en el caso de los bloqueadores virales de la vía extrínseca, o por la presencia o ausencia en el genoma al tratarse de diferente cepa viral ${ }^{17}$. También parece existir efecto diferentes según el modelo in vitro empleado, por el tipo de explante del cual las células son obtenidas y de sus condiciones de cultivo ${ }^{58}$. Por otra parte, estudios en monocitos y en CPN sugieren un fuerte efecto del estado de diferenciación celular ${ }^{62,63,65}$. De igual forma, resulta interesante que el virus emplea diversas estrategias para lograr un mismo cometido, ya que los miRNAs virales pueden actuar sinérgicamente con las proteínas virales para contrarrestar las defensas de la célula a la infección.

Asimismo ahora se contempla que además del daño que CMV causa sobre las células que infecta, también es capaz de inducir respuestas en células no infectadas. Este efecto espectador incluye la eliminación de células con el potencial de eliminar a las células hospederas del virus, así como en otros casos, la interferencia con sus funciones ${ }^{51,54,55}$.

Como ya se mencionó, una de las poblaciones con especial susceptibilidad al CMV es la de los recién nacidos y fetos, donde el cerebro es el principal sitio de infección, por lo cual es una importante causa de desórdenes neurológicos. Estudios in vitro e in vivo empleando modelos animales muestran que dentro del 
SNC, CMV es capaz de infectar prácticamente cualquier tipo de célula; no obstante, existe cierta preferencia por la infección de algunos tipos celulares. Asimismo, se ha encontrado un efecto del estado de diferenciación respecto a la adquisición de la susceptibilidad a la infección. Por otra parte, ha sido reportada la inducción de apoptosis en varios tipos celulares, incluyendo neuronas, astrocitos y CPN. Recientemente se le ha atribuido parte del daño causado por el virus a efectos sobre las CPN, al localizarse las células infectadas, principalmente en las regiones ventricular y subventricular donde residen este tipo de células. Se han relacionado algunas de las manifestaciones clínicas más frecuentes con la infección de las $\mathrm{CPN}$, como la microcefalia que podría tener su origen en la disminución de su proliferación y posterior migración, así como interfiriendo con procesos de diferenciación en estas células $^{58,66,67}$. No obstante, son necesarios más estudios que logren esclarecer los mecanismos que subyacen al daño en SNC inducido por el virus, así como las consecuencias clínicas que estos efectos tengan.

En definitiva, los efectos anti-apoptóticos de CMV representan ventajas para el virus al permitirle replicarse libremente en las células hospederas, mientras que la presencia de diversos bloqueadores pone en evidencia la necesidad de interferir con diferentes vías de señalización, en diferentes tipos celulares o de forma dependiente del tiempo para poder lograr su cometido y ser un patógeno exitoso.
Agradecimientos: Hilda González recibió la beca CONACYT (CVU/becario): 265757.

\section{Resumen}

La apoptosis representa uno de los mecanismos de defensa más eficaces frente a la propagación de patógenos como lo son los virus. No obstante, éstos han desarrollado medidas para contrarrestar el papel protector de la apoptosis en las células infectadas. Citomegalovirus (CMV) es considerado la principal causa de infecciones congénitas a nivel mundial, afectando de forma importante el sistema nervioso central (SNC) en desarrollo. Diversos mecanismos de prevención de apoptosis durante la infección por CMV han sido descritos, entre los cuales, se encuentran proteínas y ARNs virales capaces de evitar la apoptosis por las vías intrínseca, extrínseca y la mediada por estrés del retículo endoplásmico. Sin embargo, aún representa un enigma el efecto pro-apoptótico de CMV que se sugiere actúe como un efecto espectador sobre las células no infectadas. En el presente trabajo se ofrece una revisión de los mecanismos mediante los cuales CMV modula las vías de señalización involucradas en la apoptosis. Asimismo se incluye una breve descripción de la permisividad del SNC a la infección por CMV y sobre la muerte celular generada tras la infección, que pueden relacionarse con el daño observado durante una infección congénita.

\section{Referencias bibliográficas}

1.- Griffiths P D, Grundy J E. Molecular biology and immunology of cytomegalovirus. Biochem J 1987; 241 (2): 313-24.

2.- Noyola D E, Jiménez-Capdeville M E, Demmler-Harrison G J. Central nervous system disorders in infants with congenital cytomegalovirus infection. Neurological Res 2010; 32 (3): 278-84.

3.- Simanek AM, Dowd JB, Pawelec G, Melzer D, Dutta A, Aiello AE. Seropositivity to cytomegalovirus, inflammation, all-cause and cardiovascular disease-related mortality in the United States. PloS one 2011; 6 (2): e16103.

4.- Britt W. Manifestations of human cytomegalovirus infection: proposed mechanisms of acute and chronic disease. Curr Top Microbiol Immunol 2008; 325: 417-70.

5.- Tsutsui $Y$, Kosugi I, Kawasaki H. Neuropathogenesis in cytomegalovirus infection: Indication of the mechanisms using mouse models. Rev Med Virol 2005; 15 (5): 327-45.

6.- Beltrán P M J, Cristea I M. The life cycle and pathogenesis of human cytomegalovirus infection: lessons from proteomics. Exp Rev Proteomics 2014; 11 (6): 697-711.

7.- Kosugi I, Kawasaki H, Tsuchida T, Tsutsui Y. Cytomegalovirus infection inhibits the expression of N-methyl-D-aspartate receptors in the developing mouse hippocampus and primary neuronal cultures. Acta Neuropathol 2005; 109 (5): 475-82.

8.- Lin A, Xu H, Yan W. Modulation of HLA expression in human cytomegalovirus immune evasion. Cell Mol Immunol 2007; 4 (2): 91-8.

9.- Kerr J F, Wyllie A H, Currie A R. Apoptosis: a basic biological phenomenon with wide-ranging implications in tissue kinetics. Br J Cancer 1972; 26 (4): 239-57.

10.- Kajta M. Apoptosis in the central nervous system: Mechanisms and protective strategies. Pol J Pharmacol 2004; 56 (6): 689-700.

11.- Jin Z, El-Deiry W S. Overview of cell death signaling pathways. Cancer Biol Ther 2005; 4 (2): 139-63.

12.- Martin L J. Mitochondrial and cell death mechanisms in neurodegenerative diseases. Pharmaceuticals (Basel) 2010; 3 (4): 839-915.

13.- Núñez G, Benedict M A, Hu Y, Inohara N. Caspases: the proteases of the apoptotic pathway. Oncogene 1998; 17 (25): 3237-45.
14.- Zhang J. Developmental switch on the signaling for cardiomyocyte death: Insights into the regulation of apoptotic gene expression and into the control of DNA fragmentation. Universidad de Lleida, Deparment de Ciències Mèdiques Bàsiques. 2009.

15.- McCormick A L, Skaletskaya A, Barry P A, Mocarski E S, Goldmacher V S. Differential function and expression of the viral inhibitor of caspase 8-induced apoptosis (vICA) and the viral mitochondria-localized inhibitor of apoptosis (vMIA) cell death suppressors conserved in primate and rodent cytomegaloviruses. Virology 2003; 316 (2): 221-33.

16.- Norris K L, Youle R J. Cytomegalovirus proteins vMIA and $\mathrm{m} 38.5$ link mitochondrial morphogenesis to Bcl-2 family proteins. J Virol 2008; 82 (13): 6232-43.

17.- Cam M, Handke W, Picard-Maureau M, Brune W. Cytomegaloviruses inhibit Bak-and Bax-mediated apoptosis with two separate viral proteins. Cell Death Differ 2010; 17 (4): 655-65.

18.- Williamson C D, Colberg-Poley A M. Intracellular sorting signals for sequential trafficking of human cytomegalovirus UL37 
proteins to the endoplasmic reticulum and mitochondria. J Virol 2010; 84 (13): 6400-9.

19.- Zhang A, Hildreth R L, Colberg-Poley A M. Human cytomegalovirus inhibits apoptosis by proteasome-mediated degradation of Bax at endoplasmic reticulum-mitochondrion contacts. J Virol 2013; 87 (10): 5657-68.

20.- McSharry B P, Tomasec P, Neale M L, Wilkinson G W G. The most abundantly transcribed human cytomegalovirus gene (beta 2.7 ) is non-essential for growth in vitro. J Gen Virol 2003; 84: 2511-6.

21.- Babu S G, Pandeya A, Verma N, Shukla N, Kumar R V, Saxena S. Role of HCMV miR-UL70-3p and miR-UL148D in overcoming the cellular apoptosis. Mol Cell Biochem 2014; 393 (1-2): 89-98

22.- Reeves M B, Davies A A, McSharry B P, Wilkinson G W, Sinclair J H. Complex I binding by a virally encoded RNA regulates mitochondria-induced cell death. Science 2007 ; 316 (5829): 1345-8.

23.- Goldmacher V S, Bartle L M, Skaletskaya A, Dionne C A, Kedersha N L, Vater C A, et al. A cytomegalovirus-encoded mitochondrialocalized inhibitor of apoptosis structurally unrelated to Bcl-2. Proc Natl Acad Sci U S A. 1999; 96 (22): 12536-41.

24.- Dragovich T, Rudin C M, Thompson C B. Signal transduction pathways that regulate cell survival and cell death. Oncogene 1998; 17 (25): 3207-13.

25.- Skaletskaya A, Bartle L M, Chittenden T, McCormick A L, Mocarski E S, Goldmacher V S. A cytomegalovirus-encoded inhibitor of apoptosis that suppresses caspase-8 activation. P Natl Acad Sci USA 2001; 98 (14): 7829-34.

26.- Menard C, Wagner M, Ruzsics Z, Holak K, Brune W, Campbell A E, et al. Role of murine cytomegalovirus US22 gene family members in replication in macrophages. J Virol 2003; 77 (10): 5557-70.

27.- Ebermann L, Ruzsics Z, Guzmán C A, van Rooijen N, Casalegno-Garduno R, Koszinowski U, et al. Block of death-receptor apoptosis protects mouse cytomegalovirus from macrophages and is a determinant of virulence in immunodeficient hosts. PLoS Pathog 2012; 8 (12): e1003062.

28.- Baillie J, Sahlender D A, Sinclair J H. Human cytomegalovirus infection inhibits tumor necrosis factor alpha (TNF-alpha) signaling by targeting the 55-kilodalton TNF-alpha receptor. J Virol 2003; 77 (12): 7007-16.

29.- Turtinen L W, Assimacopoulos A, Haase A T. Increased monokines in cytomegalovirus infected myelomonocytic cell cultures. Microb Pathog 1989; 7 (2): 135-45.

30.- Li J, Lee B, Lee A S. Endoplasmic reticulum stress-induced apoptosis: multiple pathways and activation of p53-up-regulated modulator of apoptosis (PUMA) and NOXA by p53. J Biol

Chem 2006; 281 (11): 7260-70.

31.- Xuan B, Qian Z, Torigoi E, Yu D. Human cytomegalovirus protein pUL38 induces ATF4 expression, inhibits persistent JNK phosphorylation, and suppresses endoplasmic reticulum stress-induced cell death. J Virol 2009; 83 (8): 3463-74.

32.- Deshmukh M, Johnson E M Jr. Programmed cell death in neurons: focus on the pathway of nerve growth factor deprivation-induced death of sympathetic neurons. Mol Pharmacol 1997; 51 (6): 897-906.

33.- D'Ercole A J, Ye P. Expanding the mind: insulin-like growth factor I and brain development. Endocrinology 2008; 149 (12): 5958-62.

34.- Yu Y J, Alwine J C. Human cytomegalovirus major immediate-early proteins and simian virus 40 large $\mathrm{T}$ antigen can inhibit apoptosis through activation of the phosphatidylinositide 3 '-OH kinase pathway and the cellular kinase Akt. J Virol 2002; 76 (8): 3731-8.

35.- Liu X, Cohen J I. The role of PI3K/Akt in human herpesvirus infection: From the bench to the bedside. Virology 2015; 479-480: 568-77.

36.- Soroceanu L, Akhavan A, Cobbs C S. Plateletderived growth factor-alpha receptor activation is required for human cytomegalovirus infection. Nature 2008; 455 (7211): 391-5

37.- Chiou S H, Yang Y P, Lin J C, Hsu C H, Jhang H C, Yang Y T, et al. The immediate early 2 protein of human cytomegalovirus (HCMV) mediates the apoptotic control in HCMV retinitis through up-regulation of the cellular FLICE-inhibitory protein expression. J Immunol 2006; 177 (9): 6199-206.

38.- Casavant N C, Luo M H, Rosenke K, Winegardner T, Zurawska A, Fortunato E A. Potential role for p53 in the permissive life cycle of human cytomegalovirus. J Virol 2006; 80 (17): 8390-401.

39.- Sinclair J, Sissons P. Latency and reactivation of human cytomegalovirus. J Gen Virol 2006; 87 (Pt 7): 1763-79.

40.- Chan G, Nogalski M T, Bentz G L, Smith M S Parmater A, Yurochko A D. PI3Kdependent upregulation of Mcl-1 by human cytomegalovirus is mediated by epidermal growth factor receptor and inhibits apoptosis in short-lived monocytes. J Immunol 2010; 184 (6): 3213-22.

41.- Reeves M B, Breidenstein A, Compton T. Human cytomegalovirus activation of ERK and myeloid cell leukemia-1 protein correlates with survival of latently infected cells. Proc Natl Acad Sci U S A. 2012; 109 (2): 588-93

42.- Opferman J T, Iwasaki H, Ong C C, Suh H, Mizuno S, Akashi K, et al. Obligate role of anti-apoptotic MCL-1 in the survival of hematopoietic stem cells. Science 2005; 307 (5712): 1101-4
43.- Li H, Yuan C, Zhou Y. Human cytomegalovirus inhibits apoptosis involving upregulation of the antiapoptotic protein Bag-1. J Med Virol 2015; 87 (11): 1953-9.

44.- Kun D, Xiang-Lin C, Ming Z, Qi L. Chlamydia inhibit host cell apoptosis by inducing Bag-1 via the MAPK/ERK survival pathway. Apoptosis 2013; 18 (9): 1083-92.

45.- Perkins D, Pereira E F, Aurelian L. The herpes simplex virus type $2 \mathrm{R} 1$ protein kinase (ICP10 $\mathrm{PK}$ ) functions as a dominant regulator of apoptosis in hippocampal neurons involving activation of the ERK survival pathway and upregulation of the antiapoptotic protein Bag-1. J Virol 2003; 77 (2): 1292-305.

46.- Upton J W, Kaiser W J, Mocarski E S. Cytomegalovirus M45 cell death suppression requires receptor-interacting protein (RIP) homotypic interaction motif (RHIM)-dependent interaction with RIP1. J Biol Chem 2008; 283 (25): 16966-70.

47.- Patrone M, Percivalle E, Secchi M, Fiorina L, Pedrali-Noy G, Zoppe M, et al. The human cytomegalovirus UL45 gene product is a late, virion-associated protein and influences virus growth at low multiplicities of infection. J Gen Virol 2003; 84: 3359-70.

48.- Brune W, Nevels M, Shenk T. Murine cytomegalovirus $\mathrm{m} 41$ open reading frame encodes a Golgi-localized antiapoptotic protein. J Virol 2003; 77 (21): 11633-43.

49.- Reboredo M, Greaves R F, Hahn G. Human cytomegalovirus proteins encoded by UL37 exon 1 protect infected fibroblasts against virusinduced apoptosis and are required for efficient virus replication. J Gen Virol 2004; 85 (Pt 12): 3555-67.

50.- Pleskoff O, Casarosa P, Verneuil L, Ainoun F, Beisser P, Smit M, et al. The human cytomegalovirus-encoded chemokine receptor US28 induces caspase-dependent apoptosis. FEBS J 2005; 272 (16): 4163-77.

51.- Chiou S H, Liu J H, Hsu W M, Chen S S, Chang S Y, Juan L J, et al. Up-regulation of Fas ligand expression by human cytomegalovirus immediate-early gene product 2 : a novel mechanism in cytomegalovirus-induced apoptosis in human retina. J Immunol 2001; 167 (7): 4098-103

52.- van Den Pol A N, Mocarski E, Saederup N, Vieira J, Meier T J. Cytomegalovirus cell tropism, replication, and gene transfer in brain. J Neurosci 1999; 19 (24): 10948-65.

53.- Dash R, Lawrence M, Ho D, Sapolsky R. A herpes simplex virus vector overexpressing the glucose transporter gene protects the rat dentate gyrus from an antimetabolite toxin. Exp Neurol 1996; 137 (1): 43-8

54.- Kosugi I, Shinmura Y, Li R Y, Aiba-Masago S, Baba S, Miura K, et al. Murine cytomegalovirus induces apoptosis in non-infected cells of the developing mouse brain and blocks apoptosis 
in primary neuronal culture. Acta Neuropathol 1998; 96 (3): 239-47.

55.- Ho W S C, van den Pol A N. Bystander attenuation of neuronal and astrocyte intercellular communication by murine cytomegalovirus infection of glia. J Virol 2007; 81 (13): 7286-92.

56.- Lokensgard J R, Cheeran M C, Gekker G, Hu S, Chao C C, Peterson P K. Human cytomegalovirus replication and modulation of apoptosis in astrocytes. J Hum Virol 1999; 2 (2): 91-101.

57.- Shi B, De Girolami U, He J, Wang S, Lorenzo A, Busciglio J, et al. Apoptosis induced by HIV-1 infection of the central nervous system. J Clin Invest 1996; 98 (9): 1979-90.

58.- Odeberg J, Wolmer N, Falci S, Westgren M, Seiger A, Soderberg-Naucler C. Human cytomegalovirus inhibits neuronal differentiation and induces apoptosis in human neural precursor cells. J Virol 2006; 80 (18): 8929-39.

59.- Odeberg J, Wolmer N, Falci S, Westgren M, Sundtrom E, Seiger A, et al. Late human cytomegalovirus (HCMV) proteins inhibit differentiation of human neural precursor cells into astrocytes. J Neurosci Res 2007; 85 (3): 583-93.

60.- Tsutsui Y, Kawasaki H, Kosugi I. Reactivation of latent cytomegalovirus infection in mouse brain cells detected after transfer to brain slice cultures. J Virol 2002; 76 (14): 7247-54.

61.- DeBiasi R L, Kleinschmidt-DeMasters B K, Richardson-Burns S, Tyler K L. Central nervous system apoptosis in human herpes simplex virus and cytomegalovirus encephalitis. J Infect Dis 2002; 186 (11): 1547-57.

62.- Nakamura H, Liao H, Minami K, Toyoda M, Akutsu H, Miyagawa Y, et al. Human cytomegalovirus induces apoptosis in neural stem/progenitor cells derived from induced pluripotent stem cells by generating mitochondrial dysfunction and endoplasmic reticulum stress. Herpesviridae 2013; 4v(1): 2.

63.- González-Sánchez H M, Monsivais-Urenda A, Salazar-Aldrete C A, Hernández-Salinas A, Noyola D E, Jiménez-Capdeville M E, et al. Effects of cytomegalovirus infection in human neural precursor cells depend on their differentiation state. J Neurovirol 2015; 21 (4): 346-57.

64.- Kawasaki H, Kosugi I, Arai Y, Iwashita T,
Tsutsui Y. Mouse embryonic stem cells inhibit murine cytomegalovirus infection through a multi-step process. PloS one 2011; 6 (3): e17492.

65.- McCormick A L, Roback L, LivingstonRosanoff D, St Clair C. The human cytomegalovirus UL36 gene controls caspase-dependent and-independent cell death programs activated by infection of monocytes differentiating to macrophages. J Virol 2010; 84 (10): 5108-23.

66.- Luo M H, Hannemann H, Kulkarni A S, Schwartz P H, O'Dowd J M, Fortunato E A. Human cytomegalovirus infection causes premature and abnormal differentiation of human neural progenitor cells. J Virol 2010; 84 (7): 3528-41.

67.- Tsutsui Y, Kosugi I, Kawasaki H, Arai Y, Han G P, Li L, et al. Roles of neural stem progenitor cells in cytomegalovirus infection of the brain in mouse models. Pathol Int 2008; 58 (5): 257-67.

68.- Mellor H R, Harris A L. The role of the hypoxia-inducible BH3-only proteins BNIP3 and BNIP3L in cancer. Cancer Metastasis Rev 2007; 26 (3-4): 553-66. 